\title{
DESCOBRINDO E RECOBRINDO O PASSADO NAS SALAS DE AULA COM ASSASSIN'S CREED ORIGINS DISCOVERY TOUR
}

\author{
Nelson de Paiva Bondioli ${ }^{1}$ \\ Rodrigo Araújo de Lima $^{2}$
}

\section{RESUMO}

O presente artigo propõe uma análise a respeito do modo Discovery Tour, desenvolvido pela Ubisoft Montreal para o jogo Assassin's Creed Origins. O Discovery Tour é proposto pelos desenvolvedores como uma ferramenta "puramente educacional", entendida como um "Museu Virtual" auxiliando alunos na compreensão do passado por meio de tours guiados e a exploração de sítios históricos. Problematiza-se neste estudo a censura realizada às estátuas do mundo Greco-Romano, uma vez que essas aparecem neste - e somente neste - modo de jogo com seios e genitálias cobertas por conchas, levantando-se questões acerca do ensino e o olhar sexualizado sobre o passado.

PALAVRAS-CHAVE: Discovery Tour; Assassin's Creed Origins; Arqueologia; Educação; Queer.

\section{ABSTRACT}

The present article analyzes the Discovery Tour mode, developed by Ubisoft Montreal for the game Assassin's Creed Origins. The Discovery Tour mode is proposed by its developers as a "purely educational" tool, understood as a "Virtual Museum" aiming at aiding students to understand the past through guided tour concerning Egyptian life and its historical sites. It will be questioned in this study the censorship enacted against the nudity of Classical statues, considering that they are censored solely in this gaming mode, in which the genitals and nipples statues of Greek Gods and Goddesses appear covered by seashells, raising several issues concerning today's education and the oversexualized gaze over the past.

KEYWORDS: Discovery Tour; Assassin's Creed Origins; Archaeology; Education, Queer.

\section{RESUMEN}

El presente artículo tiene como objetivo realizar un análisis acerca del modo Discovery Tour, desarrollado por Ubisoft Montreal para el juego Assassin's Creed Origins. El Discovery Tour es propuesto por los desarrolladores como una herramienta "puramente educativa", entendida como un "Museo Virtual" que ayuda a los alumnos en la comprensión del pasado a través del Tour guiados y la exploración de sitios históricos. En este estudio se discute la censura realizada a las estatuas del Mundo Grecorromano, una vez que éstas aparecen en

\footnotetext{
1 Doutor em História pela UNESP. Atualmente desenvolvendo Pós-Doutorado na UNESP/FCL-Assis, com projeto de pesquisa: "Clássico Clássicos: Cultura Pop e Recepção da História Romana na Atualidade”, apoio financeiro PNPD-CAPES.
}

2 Mestre e Doutorando em Arqueologia pelo MAE-USP sob a orientação da Prof ${ }^{a}$. Dr ${ }^{\mathrm{a}}$. Maria Cristina Nicolau Kormikiari. membro do Labeca (Laboratório de Estudos sobre a Cidade Antiga). Bolsista CAPES. p. $\mathrm{Jul} / 2019$ 
este - y sólo en este - modo de juego con pechos y genitales cubiertos por conchas, con el fin de plantear preguntas acerca de la enseñanza y la mirada sexualizada sobre el pasado.

PALABRAS CLAVE: Discovery Tour; Assassin's Creed Origins; Arqueología; Educación; Queer.

\section{INTRODUÇÃO}

Atualmente uma das grandes questões debatidas no campo educacional, tanto na História quanto na Arqueologia é, justamente, o desafio em manter estas Ciências interessantes e relevantes para as novas gerações. As problemáticas referentes, sobretudo, à incorporação de novas metodologias e tecnologias no ensino - da educação básica ao ensino superior - têm tomado a atenção de pesquisadores e professores (cf. SANTOS, 2014), bem como instigado o interesse de empresas visando espaço em novos nichos de mercado, especialmente, o do ensino digital.

Mas o que de fato queremos dizer quando afirmamos que o ensino se utiliza de recursos tecnológicos ou digitais? De um lado, podemos observar a própria mudança nas últimas décadas sobre o entendimento, dentro das Ciências Humanas e Sociais, do papel da computação para a pesquisa científica, e a consolidação da área denominada como Humanidades Digitais $^{3}$, embora o debate sobre o que representa, não esteja definido em sua totalidade.

Nesse sentido, notamos que num primeiro momento, falar de Humanidades Digitais tratava-se de explorar uma área de trabalho "quantitativo", isto é, que se baseava principalmente na capacidade computacional de mobilizar extensos bancos de dados e criar matrizes, hoje, entende-se também como trabalho "qualitativo", "interpretativo", "experimental", "emotivo", e de caráter "generativo" (SCHNAPP; PRESNER, 2009).

É importante notar, como também aponta David Berry (2012), que este avanço, não se trata, realmente, de etapas sucessivas das pesquisas em Humanidades Digitais, mas sim de um alargamento de seu conceito e interpretação, ocorrendo, concomitantemente, diferentes formas de trabalho. Permanecem, por exemplo, ainda hoje

${ }^{3} \mathrm{O}$ termo foi cunhado em 2004 por John Unsworth, Susan Schreibman e Ray Siemens na obra de mesmo ano A Companion to Digital Humanities. Essa terminologia teria a finalidade de demonstrar as potencialidades do uso dos computadores (cf. UNSWORTH; SCHREIBMAN; SIEMENS, 2004).

\begin{tabular}{|l|c|c|c|c|c|c|}
\hline (C) Rev. Arqueologia Pública & Campinas, SP & v.13 & n.1 & p. & Jul/2019 & ISSN 2237-8294
\end{tabular}


diversos projetos de digitalização de acervos e de estabelecimento de estruturas tecnológicas (aspectos quantitativos, por assim dizer) que tem como uma de suas missões a democratização do acesso a determinados materiais; projetos esses que muitas vezes vem acompanhados de processos de interpretação e experimentação (qualitativos, portanto).

No campo de estudos da Antiguidade Clássica, os estudos em Humanidades Digitais, tem ganhando cada vez mais espaço, não apenas devido a questões orçamentárias - pois, como se sabe, há uma grande discussão acerca da alocação de fundos para departamentos de Ciências Humanas, buscando-se em contramedida um caráter prático/utilitarista para as pesquisas - mas também pelo próprio interesse de professores e pesquisadores, elemento este crescente no Brasil, visível, por exemplo, nos trabalhos apresentados no II Simpósio do LARP: "Atualizando o passado romano: Pesquisa, Educação e as Humanidades Digitais" em $2018^{4}$.

No que concerne à Arqueologia, temos inúmeros exemplos nacionais e internacionais, que não caberiam aqui, sobre pesquisas e produtos que se valeram de ferramentas oferecidas pelas Humanidades Digitais na produção e difusão do conhecimento científico. Neste artigo, dada a especificidade de nosso recorte, entenderemos Humanidades Digitais enquanto um pressuposto teórico e metodológico que se vale de ferramentas tecnológica apropriadas, via computação, para a criação de reconstituições hipotéticas em ambiente virtual.

Considerada a vastidão de possibilidades da área de estudos da Antiguidade e Humanidades Digitais, nos concentramos neste artigo em uma das áreas que tem ganhado espaço nas pesquisas acadêmicas, tanto nacional quanto internacionalmente, que é a da criação e/ou utilização de jogos digitais para se trabalhar conteúdos históricos. Calibrado tanto o conceito Humanidades Digitais quanto o termo reconstrução temos condições para avançar em nossa proposta de debate.

De um lado, há já uma extensa bibliografia a respeito da importância do aspecto lúdico na aprendizagem (cf. MOSCHINI; CAIERÃO, 2015; ALVES; BIANCHIN, 2010), bem

4 Caderno de Resumos, disponível em: http://www.larp.mae.usp.br/wpcontent/uploads/2018/05/Resumos-Simp\%C3\%B3sio-do-LARP-Completo.pdf, acessado em 21/01/2019. 
como, de outro lado, sobre a especificidade de jogos com fundo ou conteúdos históricos para se trabalhar diferentes temas nas salas de aula (cf. MCMICHAEL, 2007; MCCALL, 2016).

Cada vez mais o uso de jogos vem contribuindo para a difusão do conhecimento científico. Por meio de uma linguagem mais acessível, o saber científico é realçado de modo a se tornar claro e dinâmico durante o processo de aprendizagem.

Deve-se ter em mente, porém, que esse aspecto depende também da capacidade de recepção de recursos pelas instituições de ensino para essas possam efetivamente fazer uso das últimas produções computacionais para a educação de seus estudantes. É necessário pontuar que cada vez mais, os produtos virtuais vem exigindo requisitos mínimos ${ }^{5}$ consideráveis dos sistemas operacionais para seu funcionamento mediano e, por muitas vezes, colégios públicos brasileiros possuem menos que o mínimo e/ou não dispõem de números suficientes de computadores ou aparelhos interativos que deem conta de uma sala de aula cheia. Se essa realidade se verifica em grandes centros urbanos, as conclusões que podemos tirar para as periferias mais afastadas e nos interiores do país são pesarosas. Assim, nem sempre é possível, principalmente para a maior parte das instituições públicas de ensino nacionais, adquirir computadores que tenham capacidade para a instalação de alguns jogos, ou o uso de consoles ${ }^{6}$ para a prática didática. Inserimos, portanto, nesse debate a seguinte questão, a qual voltaremos ao final do artigo: quem terá acesso a esse conteúdo será apenas uma camada privilegiada com condições de adquirir equipamentos de ponta para o ensino? Não temos aqui a intenção de nos aprofundar nessa temática, que seria um artigo por si mesma, exigindo um estudo muito mais aprofundado focado sobre, e tão somente, nessa dificuldade. No entanto, não poderíamos deixar que destacar a barreira que se impõe perante o discurso da difusão do conhecimento pelos teóricos das Humanidades Digitais.

À baila dessa conjuntura, devemos sempre ter em mente o que é produzido, enquanto jogo eletrônico, muitas vezes é o reflexo do agir de um determinado grupo social dominante, que apresenta uma representação de seus valores, ideias e visões de mundo para os demais por meio de diferentes gêneros de jogos (e.g. Ação, Aventura, Corrida,

${ }^{5}$ Seja por requerimentos para a placa de vídeo, potência do processador, memória de acesso aleatório e o próprio custo do sistema operacionais.

${ }^{6}$ Sistemas dedicados à execução de jogos, dentre outros recursos interativos

\begin{tabular}{|l|l|l|l|l|l|l|}
\hline (C) Rev. Arqueologia Pública & Campinas, SP & v.13 & n.1 & p. & Jul/2019 & ISSN 2237-8294
\end{tabular} 
Esporte, Estratégia, Simulação, dentre outros). Desse modo, o anúncio de franquias de jogos, enquanto possíveis instrumentos de ensino por parte de grandes empresas do ramo, deve ser analisado e avaliado criticamente, para não cair na falsa ideia de que o que é apresentado ao público pode ser de fato utilizado sem questionamento prévio, realizado por especialistas de diferentes áreas, na sala de aula.

A partir destas observações iniciais, apresentamos o objeto de análise deste artigo, o jogo de videogame Assassin's Creed Origins[1] (2017) desenvolvido pela Ubisoft Montreal, em seu modo Discovery Tour, lançado no ano seguinte. Localizado, pois, justamente na intersecção de três elementos anteriormente abordados: Ensino, Humanidades Digitais e o Interesse por novos mercados. A articulação destes aspectos traz consigo a problemática específica de nosso interesse: como uma ferramenta de ensino apresenta um olhar sexualizado sobre o passado.

\section{ASSASSIN'S CREED ORIGINS E DISCOVERY TOUR}

Assassin's Creed é uma das maiores franquias de videogame da atualidade. Desenvolvida pela Ubisoft Montreal, foram lançados entre 2007 e 2018 nada menos do que vinte jogos, disponíveis para diferentes plataformas. Além disso, atingiu outros nichos de mercado, com os lançamentos de livros/romances, histórias em quadrinhos e contando, inclusive, com uma estreia hollywoodiana em 2016.

A popularidade de Assassin's Creed revela-se de maneira particularmente importante para nós em alguns números: uma estimativa da rede Moneylnc de $2016^{7}$ coloca a franquia com uma receita de $\$ 300$ milhões de dólares, e em torno de 100 milhões de cópias de jogos vendidas ao redor do mundo. Para além de seu valor multimilionário, a questão da difusão do jogo é bastante relevante, pois devemos observar a principal característica da franquia: a ideia de reconstruções interativas com sociedades do passado e, de alguma forma, a experiência de se reviver eventos históricos.

De maneira geral - e consideravelmente resumida - o enredo dos jogos de Assassin's Creed se passa na mesma realidade que a do jogador, com algumas notáveis

7 Moneylnc, https://moneyinc.com/exactly-valuable-assassins-creed-franchise/, acessado em 15/03/2018. 
exceções, das quais destaca-se a existência de um conglomerado multinacional (Abstergo Inc.), cujo objetivo é dominar, literalmente, a mente e o coração de todos os seres humanos, utilizando-se de artefatos tecnológicos de uma civilização pré-histórica já extinta (o povo Isu). Contra as pretensões totalitárias deste grupo de pessoas, estariam os assassinos buscando preservar o livre arbítrio da humanidade.

Os jogos de Assassin's Creed, portanto, giram em torno da corrida entre as duas facções por esses artefatos que, por sua vez, foram escondidos ao longo do tempo por diferentes indivíduos e cujo paradeiro atual precisa ser descoberto. Neste contexto, o jogo apresenta a peça fundamental desse quebra-cabeça: uma máquina chamada Animus que permite a determinados indivíduos reviverem memórias "geneticamente herdadas" de seus ancestrais. Assim, com o intuito de descobrir o paradeiro dos artefatos Isu - último lugar onde eles teriam sido escondidos - o jogo permite que sejam "revividos" diferentes tempos e acontecimentos históricos, envolvendo - direta ou indiretamente - estes ancestrais.

Nesse sentido, aos jogadores de Assassin's Creed foram expostas várias temporalidades, em termos de reconstruções hipotéticas: No primeiro jogo, que se passa em 1191 E.C., apresentou-se como pano de fundo a terceira cruzada e as recriações/reconstruções de Jerusalém, Damasco e Acre. Em seguida, foram lançados jogos se passando entre 1476-1512, focando na Renascença Italiana e as cidades de Florença, Veneza e Roma. Foram desenvolvidos jogos que se passavam do Período Colonial à Revolução Americana (1500-1776), bem como pela chamada "Idade de Ouro" da Pirataria nos mares caribenhos, nos quais os jogadores podiam andar livremente por Nassau, Havana, Kingston e muitas outras localidades.

Seguindo esta premissa, foi lançado em 2017 o jogo Assassin's Creed Origins[2] que leva os jogadores ao Egito entre os anos de 49-44 a.E.C., isto é, ao final do período Ptolomaico. O pano de fundo histórico do jogo, portanto, se dá com o crescimento da influência romana no Egito, particularmente expresso na disputa pelo trono entre Cleópatra e seu irmão Ptolomeu XIII, e a interferência de Júlio César com o enredo culminando com seu assassinato no Senado.

Embora não seja diretamente o objeto deste artigo, cabe tecer algumas considerações sobre o jogo em si, do ponto de vista histórico-arqueológico. ACO foi criado junto com um grupo de historiadores, encabeçado por Maxime Durand - responsável pela 
parte histórica da franquia desde 2011 - bem como pelo trabalho do arqueólogo francês Jean-Claude Golvin, responsável por criar uma série de pinturas com reconstruções hipotéticas dos diversos sítios arqueológicos visitados no jogo (como, por exemplo, o Platô de Gizé e a cidade de Alexandria).

De fato, notamos também, como aponta a reportagem do jornal The Guardian ${ }^{8}$ (2017), um grande número de acadêmicos renomados esteve envolvido com este projeto, devido ao objetivo da franquia em trazer uma experiência "realista", do ponto de vista histórico-arqueológico e mesmo linguístico, para os jogadores.

Torna-se interessante frisarmos, sobre este tema, os comentários de Jeffrey Clark em seu artigo The Fallacy of Reconstruction (2010), em que afirma que os arqueólogos tendem a afirmar que realizaram reconstruções de alguma faceta do passado quando de fato eles não podem reconstruir o passado, mas apenas construir simulações sobre o mesmo. O termo, ainda segundo o autor, dá a ideia de que algo foi criado tal como teria sido. Salientamos aqui o termo reconstituições hipotéticas enquanto uma saída possível para lidar com as representações virtualizadas do passado uma vez que não é possível reconstituir com plena fidelidade como teriam sido as estruturas pretéritas (2010, p. 63-64).

No ínterim desse debate podemos também pensar na virtualização de estruturas enquanto uma construção temporária, baseada em um conhecimento que progride com o avanço das pesquisas arqueológicas sobre um passado. A partir desse ponto, questionamos as reconstituições que tentam a fidedignidade sobre o estruturas pregressas. Essas tentativas que se apresentam enquanto uma realidade são, no entanto, construções produzidas por um determinado grupo imersos em valores culturais atuais díspares dos que vigoravam na Antiguidade, fazendo com que as chamadas reconstruções sejam, portanto, visões anacrônicas, às vezes idealizadas em demasia, sobre a condição do passado .

$8 \quad$ Notícia disponível em: https://www.theguardian.com/technology/2017/oct/05/assassinscreed-origins-recreated-ancient-egypt-ubisoft, acessado em 15/03/2018.

$9 \quad$ Nesse tocante, devemos ter em mente que as inovações tecnológicas aliadas à uma metodologia consistente de análise nos mostram por meio de luz ultravioleta que, de fato, as estátuas gregas e romanas foram, se não em sua totalidade, pintadas com cores vibrantes durante a Antiguidade. Evidência que por si já torna anacrônico o nosso olhar acostumado à típica brancura prístina da estatuária antiga. Não abordaremos sobre esse outro aspecto uma vez que tomaria grande parte do nosso debate fugindo do nosso objeto de análise, no entanto, é preciso ter em mente também essa outra questão enquanto uma das inúmeras variáveis anacrônicas da nossa leitura sobre o passado. Disponível em: https://goo.gl/gtL9RR, acessado em 26/02/2019.

\begin{tabular}{|l|l|l|l|l|l|l|}
\hline (c) Rev. Arqueologia Pública & Campinas, SP & v.13 & n.1 & p. & Jul/2019 & ISSN 2237-8294 \\
\hline
\end{tabular} 
Em fevereiro de 2018, quatro meses após o lançamento de $A C O$, a Ubisoft Montreal distribui gratuitamente para todos aqueles que haviam comprado o jogo, um novo modo de se experimentar a franquia, o chamado Discovery Tour.

O Assassin's Creed Origins Discovery Tour [3], nas palavras da própria empresa, é "um modo que permitirá a você explorar o antigo Egito sem ser interrompido por combates ou tarefas. Puramente educacional, o modo é um "museu virtual" sem perigos, mas sim com Tour guiados e locais históricos para se descobrir"10. (grifo nosso).

\section{MUSEU: DISCURSOS, EXPOSIÇÕES E NARRATIVAS}

A partir dessas afirmações dos desenvolvedores de ACODT, é pertinente - e necessário - entender museu enquanto conceito e para tanto, trataremos brevemente sobre transição destas instituições de um período de locais de exposição e construção da memória nacional para o momento atual, em que novas vozes surgem com a intenção de transformar as instituições museológicas em ambientes onde vigoram debates sobre as mais variadas formas de humanidade. Essa reduzida síntese tem apenas como objetivo demonstrar como as instituições museológicas chegaram ao atual estado em que estão e como o conceito museu deve ser aplicado com cautela uma vez que pode ofuscar todo o histórico

de sua concepção.

Maria Cristina Bruno (2008) afirma que as instituições museológicas nasceram enquanto produto das colonizações europeias do século XVIII. Percebemos que esse aspecto reverberou nas instituições museológicas tornando-as uma ferramenta de legitimação e domínio de uma identidade nacional selecionada sobre outras.

No entanto, ainda de acordo com a autora, a experiência museológica vem se reproduzindo e se reinventando de modo a dar tratamento às questões que envolvem a condição humana, dignificando suas ações, preservando sua referência cultural, dando condições para a construção de processos históricos e identitários dos mais variados grupos sociais (BRUNO, 2008, p. 146).

${ }^{10}$ Disponível em: https://support.ubi.com/en-gb/Faqs/000031846/Discovery-Tour-Mode-of-Assassin-sCreed-Origins-ACO acessado em 15/03/2019.

\begin{tabular}{|l|l|l|l|l|l|l|}
\hline (c) Rev. Arqueologia Pública & Campinas, SP & v.13 & n.1 & p. & Jul/2019 & ISSN 2237-8294
\end{tabular} 
Bruno reconhece que há sérios problemas institucionais nos museus atuais, tais como as constantes discussões a respeito da devolução de material arqueológico e/ou etnológico bem como a dificuldade em se aplicar estudos interdisciplinares que visem a diversificação dos discursos em suas exposições (2008, p. 148).

Essa conceituação vai de acordo com a atual proposta, que data da 21ํㅗ Assembléia Geral ocorrida em Viena (Áustria) em 24 de agosto de 2007, do International Council of Museums (ICOM). Esse organismo internacional define o museu enquanto:

A museum is a non-profit, permanent institution in the service of society and its development, open to the public, which acquires, conserves, researches, communicates and exhibits the tangible and intangible heritage of humanity and its environment for the purposes of education, study and enjoyment.

Se, como apontado por Michel Shanks e Cristopher Tilley (1992, p. 68) as instituições museológicas físicas podem deturpar o passado, distorcendo-o por meio da seleção do que será exibido e como será disposto, reestruturando-o para a criação de uma narrativa coerente para a visitação, o que podemos então supor sobre essa nova experiência interativa digital onde o museu é virtualizado e pode ser acessado e visitado pelo guiar de um controle de videogame?

ACODT, conforme visto, se propõe como uma ferramenta de ensino, tornando-se um marco importante na indústria de jogos. De um lado, ele busca se afastar do caráter primariamente lúdico, como produto de entretenimento dos jogos da franquia; de outro lado é a primeira vez que uma grande franquia de jogos (conhecida em inglês como triple $A$ ) se volta especificamente para o campo da educação, como um "museu virtual" se propondo a ser utilizado em salas de aula.

Nesse sentido, cabe ainda observarmos que a própria terminologia de "Museu Virtual", como afirma Schweibenz (2004), ainda carece de uma maior definição uma vez que uma série de diferentes de projetos e visões tanto técnicas quanto museológicas aparecem no contexto do espaço virtual e da própria rede de computadores. Entretanto, localizamos a experiência do Museu Virtual especialmente próxima das problemáticas ligadas ao acesso e disponibilidade da informação, e das novas relações que se fazem entre exposições e o engajamento de seus públicos (cf. BARBIERI, L., BRUNO, F., MUZZUPAPPA, M., 2017., PIVEC, M., KRONBERGER, A., 2016). 
O problema, como aprofundaremos mais adiante, se dá quando a nudez de estátuas passou a ser um incômodo para a "exposição". A censura, no modo tour do jogo, é realizada ao adicionarem conchas completamente descontextualizadas - evidencia um modo de pensar conservador - separando o corpo sexual e reprodutor do seu restante. Essa escolha torna o jogo, portanto, um reflexo do pensamento ocidental atual reinterpretado em um contexto histórico pretérito, fato que distorce o que é conhecido até o momento sobre o que aconteceu no passado, difundindo uma informação infundada para o público que tem acesso à essa franquia de jogos. A desenvolvedora do jogo anunciou ${ }^{11}$ que "o Discovery Tour poderá ser jogado por crianças juntamente acompanhadas de seus pais e adolescentes em casa ou nas escolas, em todos os países".

Como alerta Timothy Insoll (2007, p. 1-15) a Arqueologia contribuiu pouco para as questões relacionadas à identidade. Ainda para esse autor vivemos em uma era única onde várias identidades podem ser mascaradas - em sua superfície pelo menos - por uma cultura material de natureza global. Como muito bem dito por Insoll o que acontece por detrás dessa "concha" pode significar que identidades estão sendo trabalhadas e retrabalhadas de muitas maneiras de modo a criar uma identidade fabricada dentro de moldes globalizados.

\section{DESCOBRINDO E RECOBRINDO O PASSADO: UM OLHAR SEXUALIZADO}

Comecemos nossa discussão a respeito do $A C O D T$, a partir desta última constatação: que seus desenvolvedores o planejaram com a ideia de um "museu virtual"/ ferramenta de ensino. Essa discussão passa, de maneira muito próxima, das análises aqui a serem realizadas, tendo em vista o papel crítico a ser adotado frente ao que foi produzido.

Como já apontamos anteriormente, a interpretação sobre museus e seus papéis, especialmente no que tange a museus de História, tem mudado consideravelmente desde meados do século passado. Questões primordiais a respeito das exposições passam a ser colocadas como:

$11 \quad$ Notícia disponível em: https://www.pcgamesn.com/assassins-creed-origins/assassins-creedorigins-discovery-tour-nude-statues-censorship, acessado em 26/02/2019.

\begin{tabular}{|l|l|l|l|l|l|l|}
\hline (C) Rev. Arqueologia Pública & Campinas, SP & v.13 & n.1 & p. & Jul/2019 & ISSN 2237-8294
\end{tabular} 
Quem é dono do passado? O que dá autoridade para falar por outros? Quem eu incluo e quem eu excluo? As memórias de quem serão privilegiadas, e de quem passarão de lado? Como generalizar sem ignorar? E como realizar a mediação entre a memória individual e a interpretação geral das histórias? (BEIER-DE HAAN, 2006, p. 187)

Esses questionamentos formam um importante reflexo sobre a mudança das exposições em museus que, conforme observado, partiram da perspectiva das "grandes histórias" e dos Estados Nacionais, para os temas ligados à vida cotidiana das pessoas, bem como parte de um conjunto maior de reflexões nas Ciências Humanas acerca das problemáticas dos discursos, especialmente no que tange ao local de produção/fala, construção e manutenção de identidades/alteridades.

Nesse sentido, ACODT aborda conteúdos tanto de uma perspectiva dos "grandes temas e personagens históricos" quanto de uma concepção mais atual: os "Tour" passam por tópicos tradicionais da Arqueologia e da História como a construção de Alexandria e das pirâmides, às questões e aspectos do cotidiano por meio tanto da cultura material quanto da documentação, acerca da alimentação, a domesticação de animais e o dia-a-dia dos artesões, relações do e com o corpo, saúde e higiene, para citar alguns exemplos.

Essa ambiguidade de ACODT talvez seja sua característica mais importante no que tange este trabalho, pois invoca as questões fundamentais enunciadas: na tensão entre o atual e o tradicional, a quais pressões ou grupos de pressões estão submetidos os produtos desenvolvidos pelas grandes companhias, no caso em pauta, avalia-se como se determinou o conteúdo e a apresentação do modo Tour do jogo.

É necessário relembrar, que $A C O D T$ não é, de fato, uma ferramenta "puramente educacional" mas um produto de mercado, buscando atender determinadas demandas ainda que difusas e de setores variados -, e cujo resultado final, trouxe-nos uma problemática específica: a censura de estátuas, ao estilo Greco-Romano, de seus mamilos e genitálias, conforme as imagens 1, 2, 3 e $4^{12}$.

12 Todas as imagens neste artigo foram capturadas diretamente dos respectivos modos de jogo, pelos autores deste artigo. Seu uso encontra-se respaldado nas políticas de fair use sem fins lucrativos. 
Observe-se que de um lado as imagens 1 e $\mathbf{3}$ foram retiradas do modo normal de jogo, enquanto que, do outro lado, as imagens 2 e $\mathbf{4}$ foram retiradas do modo "puramente educacional". Especificamos que, foram colocadas apenas estas imagens exemplos, exclusivamente por uma questão de espaço, uma vez que todas as estátuas que aparecem no modo Tour, apresentam-se com as conchas "da vergonha".

A partir de todos esses elementos, torna-se necessário pontuarmos: por que da necessidade dos desenvolvedores do jogo de recobrir - ou envergonhar? - as estátuas em seu modo "puramente educacional", refletindo sobre quais discursos de nossa atualidade acerca da intersecção entre nudez e educação podem ser identificados.

Em um primeiro nível, é possível questionar diretamente problemáticas ligadas à materialidade do corpo: da necessidade da censura das genitálias à equiparação de seios e mamilos femininos com órgãos sexuais.

De acordo com Rob Cover (2003, p. 55) historicamente a nudez foi representada pela sociedade ocidental intimamente relacionada à sexualidade e ao sexo, sendo classificada, por muitas vezes como indecente, imoral e obscena por influência judaicocristã, essa última que influenciou substancialmente o pensamento ocidental. Por mais que os séculos XX e XXI tenham limado os preceitos mais críticos dessas duas crenças, o residual ainda perdura, estando presente nas mais variadas formas de representação.

Cover sugere que é necessário uma completa reformulação do pensar sobre a sexualidade. A partir dessa ideia, para esse autor, a Teoria Queer faria contribuições úteis nesse repensar uma vez que, de acordo com os estudiosos freudianos, marxistasfreudianas e feministas marxistas, a sexualidade estaria restrita à genitália enquanto o resto do corpo seguiria fadado ao trabalho (COVER, 2003, p. 67).

À baila das questões de nudez é necessário uma reflexão também sobre a questão da diferenciação de gênero. Tópico que influencia profundamente nosso olhar sobre o corpo humano. A filósofa Judith Butler (1990, p. 70) sugere que a questão do gênero deve ser naturalizada, fato que requereria pensarmos as partes do corpo não enquanto seções compartimentadas, mas enquanto uma unidade indivisível. Essa questão se aprofunda no fato da determinação social em definir as áreas do corpo e crer que o 
prazer reside no pênis, na vagina e nos seios, e nos mamilos femininos, diferenciados dos masculinos.

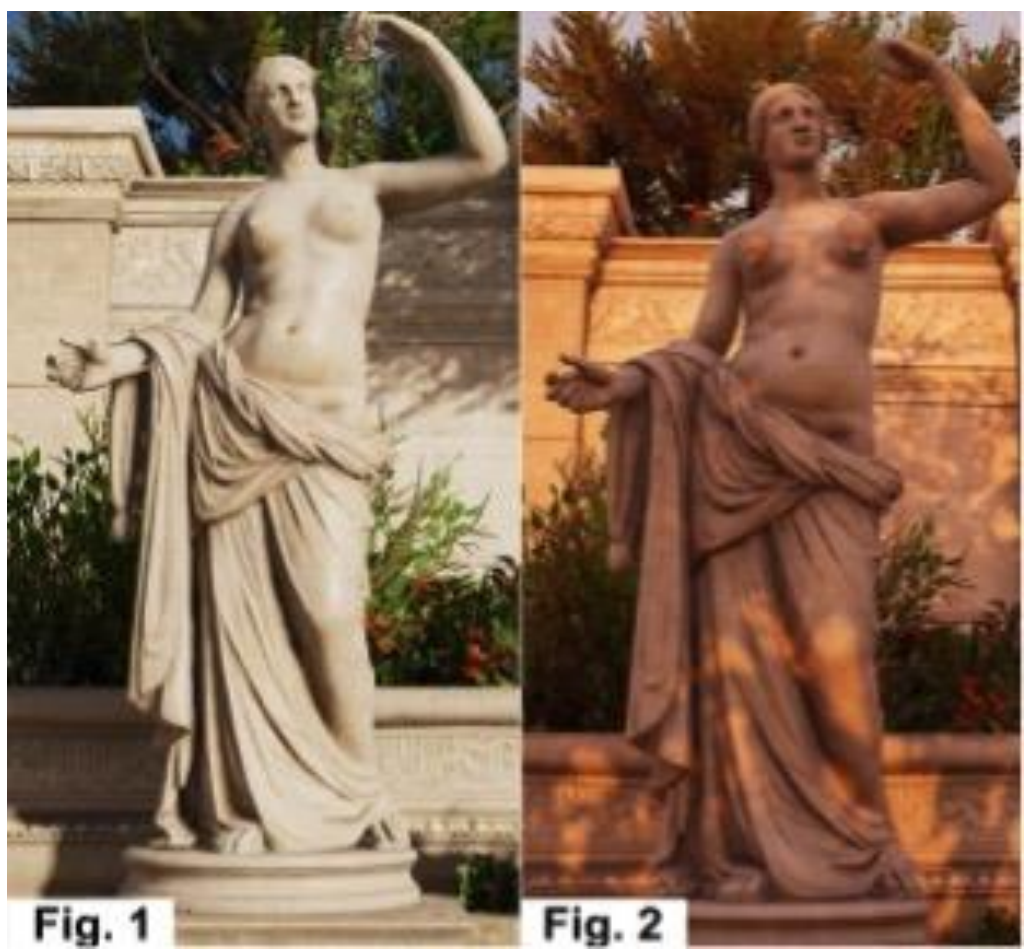

Figura 1. Estátua de Afrodite durante o modo Tour (autoria própria, 2019)

Figura 2. Estátua de Afrodite durante o jogo (autoria própria, 2019) 


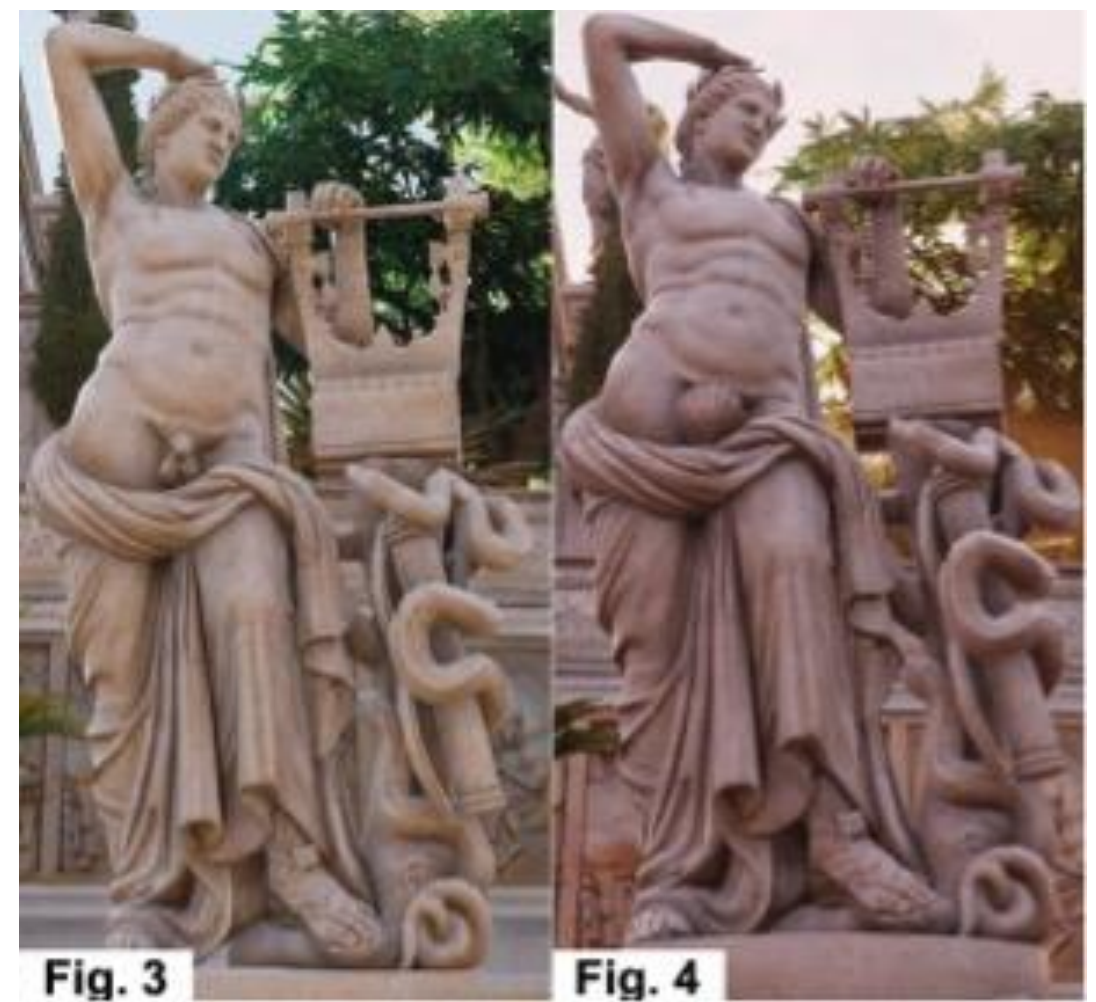

Figura 3. Estátua de Apolo durante o modo Tour (autoria própria, 2019)

Figura 4. Estátua de Apolo durante o jogo (autoria própria, 2019)

Ora, essa concepção seria, nada mais, a já construída especificidade de cada gênero (i.e. novamente, as partes do corpo seriam pensadas enquanto repartições com diferentes funções, algumas seriam, portanto, focos de prazer justamente por corresponderem à ideia normativa do corpo feminino e do masculino). À esteira dessa questão Butler (1990, p. 70) afirma que algumas dessas partes desempenhariam a função da vida enquanto outras estariam focadas no prazer e nos faz a seguinte questão: qual prazer deve viver e qual deve morrer?

Essa questão deve ser o ponto de partida de nossa reflexão uma vez que é ela que legitima as práticas de formação de identidades e ditam comportamento de cerceamento ao corpo como o que está sobre nossa análise.

Butler (1990, p. 115) reitera que "nomear o sexo é um ato de dominação e compulsão, uma performance institucionalizada que tanto cria quanto legisla a realidade social por demandar a construção discursiva/perceptiva dos corpos de acordo com os princípios da diferença sexual". A autora resume a ideia afirmando que estaríamos compelidos à pensarmos nosso corpo e mente enquanto correspondentes exatos da \begin{tabular}{|l|l|l|l|l|l|l|}
\hline (c) Rev. Arqueologia Pública & Campinas, SP & v.13 & n.1 & p. & Jul/2019 & ISSN 2237-8294 \\
\hline
\end{tabular} 
natureza estabelecida para nós, assim homem e mulher seriam categorias políticas e não fatos naturais.

Seria, assim, interessante saber quem de fato deu a ordem para a execução da censura das estátuas. Se teria sido um homem ou uma mulher, sua etnia, suas crenças, sua carreira, sua posição, qual seria seu histórico social e quais seriam seus valores. Isso resultaria em um verdadeiro trabalho de contextualização. Com isso não queremos realizar um "tribunal de inquisição" sobre um ou vários indivíduos, mas demonstrar a necessidade em se saber o contexto para perceber os nuances da dominação dos discursos bem como ele se repete em diversos níveis. Para além das identidades, teriam sido regulações governamentais? Seriam diretrizes regulatórias que, historicamente, especificam a idade mínima para os jogadores? Se utilizam leis truncadas que fazem vista grossa para produções/produtos voltadas para o entretenimento e que usam, de fato, o sexo para angariar público? Por isso a necessidade, quiçá imposição, em se colocar conchas sobre corpos nus que, durante todo o jogo, estão expostos pelas cidades egípcias?

Ademais, faz-se necessário articular este produto com sua entrada no mercado, levando-nos diretamente a reflexão a respeito do que poderíamos sumarizar como a "Crise dos Mamilos" que assola, já a mais de uma década, grande parte da produção do entretenimento norte-americana, inclusive no mundo dos games. Apesar da Ubisoft Montreal, como indicado no próprio nome, tratar-se de uma empresa com sede no Canadá, é inegável que hoje o maior mercado de jogos digitais - e mesmo do entretenimento em geral - acaba sendo o mercado norte-americano e, portanto, desenvolvedores e produtores preocupam-se com as especificidades culturais estadunidenses.

Nesse sentido, observamos que percorre pelos EUA e sua indústria cultural as ideias da nudez como necessariamente sexual, e mesmo da "obscenidade" específica dos mamilos. Basta lembrarmos que já em 2003, os mamilos de Angelina Jolie foram "censurados" dos pôsteres de divulgação do filme Tomb Raider, baseado no jogo de computador homônimo. De fato, de acordo com as regras de classificação de conteúdo do país, a nudez, mamilos inclusive, podem aparecer "brevemente" para produtos de classificação PG-13 ou PG-R - isto é, não indicados a menores de 13 e 17 anos respectivamente - e desde que em "contextos não sexuais" (MPAA, 2010). 
De maneira semelhante, a ESRB - Entertainment Software Rating Board, órgão que produz as diretrizes sobre classificação de conteúdo para jogos digitais, classifica como M-Mature - ou seja, inadequado para menores de 17 anos - a presença de conteúdo sexual, incluindo-se para eles neste subgrupo "sexual" tanto a "nudez total" quanto a "nudez parcial"13.

O problema assim, torna-se claro: trata-se do idiossincrático olhar contemporâneo que sexualiza os corpos e a nudez, sobretudo num corte de gênero em que o os seios/mamilos femininos são necessariamente "obscenos", enquanto os mamilos masculinos tidos como "naturais" e desprovidos de sexualidade, ou ainda, resgatando o linguajar de Butler, não focados no prazer.

En passant, no que tange às formas de censura aos órgãos genitais, sabemos que as estátuas gregas e romanas já em contexto medieval foram salvaguardadas pelo Vaticano e intencionalmente censuradas ${ }^{14}$ pelos papas com folhas de figo, tal como a cópia do século III-IV a.E.C. do Apolo de Belvedere (Vaticano. H. 2.24) e o Apoxyomenos de Lísipo (Vaticano. H. 2.05) do século IV a.E.C. (BOARDMAN, 1995, fig. 35.1, fig.64). (cf. TAHINCI, 2008).

Podemos considerar o ato da censura uma violência contra o possível conceito original das estátuas, fato que mais ofusca do que esclarece o que sabemos sobre o passado, bem como ecoa profundamente no funcionamento da sociedade atual. Do olhar antigo muito dificilmente recuperaríamos sua interpretação na íntegra, uma vez que estamos inseridos na episteme de nossos dias.

Em um segundo nível, decorrente pois destas primeiras observações, encontramos o problema pedagógico: Por que estudantes não podem entrar em contato

\footnotetext{
13 Classificação de Conteúdo e Descrições disponíveis online em: http://www.esrb.org/ratings/ratings_guide.aspx\#descriptors, acessado em 21/02/201.
}

14 Algumas dessas estátuas com as folhas de figo podem ser consultadas nas obras Greek Sculpture: the Classical Period (1995: fig. 63) e em Greek Sculpture: The Late Classical Period (1995, fig. 35, fig. 64), ambas de John Boardman e Hellenistic Sculpture (2005, fig. 47, fig. 143, fig. 148, fig. 150, fig. 152, fig. 156, fig. 157.1-4, fig. 160, fig. 165) de Roland Ralph Redfern Smith. É interessante notar que do período Arcaico, tudo nos leva a crer que as estátuas dessa época não foram censuradas tal como é possível perceber na obra de Boardman Greek Scultpture: The archaic period (1996), o início da implantação de folhas de figo parece principiar, e se focar, nas originais em cópias das estatuária do período clássico, tardio e helenístico.

\begin{tabular}{|l|l|l|l|l|l|l|l}
\hline (C) Rev. Arqueologia Pública & Campinas, SP & v.13 & n.1 & p. & Jul/2019 & ISSN 2237-8294 \\
\hline
\end{tabular}


com a nudez, especialmente se dentro de um contexto absolutamente tolerante, como o museológico, tal qual pretendido pelos desenvolvedores de ACODT?

Se, de um lado, conforme observado, existem conjuntos normativos a respeito da utilização da nudez nos produtos de entretenimento, é mais do que necessário efetuarmos uma crítica a respeito de buscar enquadrar objetos históricos e artefatos arqueológicos dentro de uma política de controles de corpos e sexualização da nudez.

Em primeiro lugar é preciso contextualizar as estátuas dentro do ambiente sóciocultural que as produziu. Nesse sentido, conforme demonstrou Caroline Vout a longa tradição artística Clássica não pode ser reduzida ao sabor do pitoresco sexual. Segundo a autora, devemos fugir das explicações anacrônicas das representações artísticas antigas do sexo e da nudez, como criações de fundo "obsceno" ou "pornográfico" (VOUT, 2013). Aliás, lembremos que as formas de se ver e compreender a sexualidade, entre antigos e modernos, é essencialmente diferente, elemento este que o próprio Foucault (1985) já trouxe ao apontar que a sexualidade é sempre um construto culturalmente específico, localizável no tempo e no espaço.

A exposição da nudez na arte greco-romana, segundo Vout, é menos uma ligação com o sexo, e mais como formas diferentes de interação com o mundo. Por meio de uma análise das convenções do corpo nu nas diferentes estátuas gregas, a autora aponta para o fato de existir uma complexa intersecção entre desejos, atitudes para com o divino, e a relação íntima entre objeto e observador, de modo que nestas estátuas "não se trata a respeito da nudez satisfazendo o observador; mas sim do poder da nudez de interrogá-lo" (VOUT, 2013, p. 69).

Sob o ponto de vista, portanto, meramente histórico, recobrir - e novamente, envergonhar? - as estátuas greco-romanos é uma atitude no mínimo anacrônica que, se levada às últimas consequências, representa uma total incompreensão do objeto em exposição, frustrando assim, por completo, qualquer tentativa de tornar-se educativo.

Do ponto de vista pedagógico, por sua vez, os alunos perdem em diversas frentes: do científico, conforme apontado, ao estético-artístico. Privados da total potencialidade das obras, de sua riqueza artística e profundidade de significados históricos, reproduz-se no ambiente escolar nada mais que discursos contemporâneos que condenam o corpo e 
simbolicamente o criminalizam. Se reproduz também uma perversa consequência de nossa sociedade capitalista: aqueles que têm recursos o suficiente, podem experimentar em "primeira mão" os objetos, seja por viagens em família ou mesmo pela capacidade de adquirir para si o jogo, e experimentar seu modo tradicional em que as estátuas não são censuradas. A aqueles que não possuem recursos financeiros suficientes, resta apenas vivenciar aquilo que lhe é permitido e previamente censurado.

\section{CONSIDERAÇÕES FINAIS}

Com base nas discussões realizadas, podemos notar que não existe nenhuma razão sensata que justifique o encobrimento dos mamilos e das genitálias de todos os conjuntos escultóricos no modo ACODT, especialmente considerando-se que os desenvolvedores buscaram apresentá-lo como uma ferramenta educativa no formato de um museu virtual.

Afinal, que museu virtual é esse que censura sua exposição e vai contra os próprios princípios da ICOM? Na esteira de novas abordagens museográficas, de discussões conceituais a respeito da relação dos corpos, da sexualidade e da nudez, como uma empresa realiza a censura de estátuas gregas e romanas, reforçando discursos negativos e punitivos aos jovens, nomeando o pudismo enquanto mote de sua exposição? Que relação queremos construir com crianças e adolescentes, futuros adultos, sobre o corpo humano?

Resta-nos notar, porém, que não é possível colocar a culpa exclusivamente sobre os ombros dos desenvolvedores do jogo, pois, conforme mencionado diversas vezes, tratase de um produto de mercado, que, em última análise, busca o lucro para a empresa que o produziu. Assim, cabe refletir para além dos envolvidos na produção da franquia, sobre os mercados em que a empresa pretende se inserir e dos conjuntos regulatórios aos quais está submetida.

Nesse sentido, a questão mais importante que deixamos para reflexão a se fazer sobre o jogo e, talvez, sobre nossa própria sociedade atual é: Por que uma empresa considera mais fácil censurar a nudez de estátuas milenares à discutir com órgãos de 
indicação de conteúdo, ou mesmo com a própria sociedade, o papel das artes e objetos históricos na formação de jovens?

\section{REFERÊNCIAS BIBLIOGRÁFICAS}

ALVES, Luciana; BIANCHIN, Maysa. O Jogo como Recurso de Aprendizagem. Revista Psicopedagogia, São Paulo, vol. 27, n. 83, p. 282-287, 2010.

BARBIERI, Loris; BRUNO, Fabio; MUZZUPAPPA, Maurizio. Virtual museum system evaluation through user studies. Journal of Cultural Heritage, v. 26, p. 101-108. 2017.

BEIER-DE HAAN, Rosmarie. Re-Staging Histories and Identities. In: Macdonald, Sharon. (ed.) A Companion to Museum Studies. Oxford: Blackwell Publishing, p. 186-198, 2006.

BERRY, David. Understanding Digital Humanities. New York: Palgrave Macmillan, 2012.

BOARDMAN, John. Greek Sculpture: The Archaic Period. London: Thames and Hudson, 1996.

BOARDMAN, John. Greek Sculpture: The Classical Period. London: Thames and Hudson, 1995.

BOARDMAN, John. Greek Sculpture. The Late Classical Period. London: Thames and Hudson, 1995.

BRUNO, Cristina. Museus, identidades e patrimônio cultural. Revista do Museu de Arqueologia e Etnologia. Suplemento 7. São Paulo, 2008, p. 145-151.

BUTLER, Judith. Gender Trouble. New York; London: Routledge. 1990.

CLARK, Jeffrey. The Fallacy of Reconstruction In: FORTE, Maurizio. (ed.). CyberArchaeology. Oxford: Archaeopress, BAR v. 2177, p. 63-74, 2010.

COVER, Rob. The Naked Subject, Context and Sexualization in Contemporary Culture. In: Body \& Society, vol. 9. n. 3, London; Thousand Oaks; New Dehli: Sage Publications, p. 53-71, 2003.

FOUCAULT, Michel. História da Sexualidade: O Cuidado de Si. v 3. Rio de Janeiro: Edições Graal, 1985.

INSOLL, Timothy. Introduction: configuring identities in archaeology. In: INSOLL, Timothy (ed.). The Archaeology of Identities: A Reader. London; New York: Routledge, 2007, p. 118.

MCCALL, Jeremiah. Teaching History with Digital Historical Games: An Introduction to the Field and Best Practices. In: Sage, v. 47, n. 4, p. 1-26, 2016.

MCMICHAEL, Andrew. PC Games and the Teaching of History. In: The History Teacher, v. 40, n. 2, p. 203-218, 2007.

\begin{tabular}{|l|l|l|l|l|l|l|}
\hline (C) Rev. Arqueologia Pública & Campinas, SP & v.13 & n.1 & p. & Jul/2019 & ISSN 2237-8294
\end{tabular}


MOSCHINI, Rosanita; CAIERÃO, lara. O Brincar na Clínica Psicopedagógica. Revista Psicopedagogia, São Paulo, v. 32, ed. 99, p. 361-365, 2015.

MPAA. Classification and Rating Rules. Sherman Oaks \& Washington: 2010.

PIVEC, Maja; KRONBERGER, Anika. Virtual Museum: Playful Visitor Experience in the Real and Virtual World. 8th International Conference on Games and Virtual Worlds for Serious Applications (VS-GAMES), p. 1-4. 2016.

SANTOS, Dominique. De tablet para tablet - novas ferramentas para a pesquisa e o ensino da história das culturas cuneiformes na era digital. Revista Tempo e Argumento, Florianópolis, v. 6, n. 12, p. 212 - 241, mai./ago. 2014.

SCHREIBMAN, Susan; SIEMENS, Raymond; UNSWORTH, John (eds.). A companion to Digital Humanities. Malden; Oxford; Victoria: Blackwell Publishing, 2004.

SCHWEIBENZ, Werner. The Development of Virtual Museums. ICOM News, v.57, n. 3, p.3. 2004.

SHANKS, Michael; TILLEY, Christopher. Reconstructing Archaeology: theory and practice. Cambridge, Cambridge University Press, 1992.

SMITH, Roland. Hellenistic Sculpture. London: Thames \& Hudson World of Art, 2005.

TAHINCI, Anna. Removing the feags leaf: todays Nudity in the American Public Eye.

Sculpture Review. vol. 57, n. 2 p. 16-23, 2008.

VOUT, Caroline. Sex on Show: Seeing the Erotic in Greece and Rome. London: British Museum Press, 2013.

\section{Sites*}

*Para evitarmos a poluição visual das referências aos sites, os links foram encurtados.

\section{The Guardian}

Disponível em: https://www.theguardian.com/technology/2017/oct/05/assassins-creed-originsrecreated-ancient-egypt-ubisoft, acessado em $25 / 04 / 2019$

ICOM - International Council of Museums

Disponível em: https://icom.museum/en/, acessado em 16/02/2019

\section{Ubisoft}

Disponível em: https://support.ubi.com/en-gb/Faqs/000031846/Discovery-Tour-Mode-of-Assassins-Creed-Origins-ACO, acessado em 25/04/2019

PC Games News (PCGamesN)

Disponível em: https://www.pcgamesn.com/assassins-creed-origins/assassins-creed-originsdiscovery-tour-nude-statues-censorship, acessado em 20/02/2019

Schnapp, J. and Presner, P. (2009), 'Digital Humanities Manifesto 2.0', accessado em $14 / 08 / 2010$ 


\section{Smithsonian}

Disponível

em:

https://www.smithsonianmag.com/arts-culture/true-colors17888/?c=y\&page=3, acessado em 26/02/2019

[1] Denominado a partir deste momento apenas como $A C O$

[2] Daqui em diante referido como $A C O$

[3] Daqui em diante referido apenas como ACODT

\section{AGRADECIMENTOS}

Gostaríamos de agradecer tanto o Prof. Dr. Claudio Walter Goméz Duarte (Universidade de Metropolitana de Santos) pelas indicações de leituras específicas sobre as esculturas na Antiguidade quanto ao Prof. Dr. Gilberto Francisco da Assis (Universidade Federal de São Paulo) pelos esclarecimentos também sobre essa temática. Assumindo, porém, os autores deste artigo total responsabilidade pelas interpretações e discussões apresentadas. 